\title{
Mobility development through public transportation, the case of Mexico City
}

\author{
José Antonio Valles Romero, Cid Leana Morales, Julio Márquez Rodriguez \\ Logistics and Transportation Engineering, Polytechnic Metropolitan University of the Hidalgo State, Mexico \\ Email address: \\ jvallesr@upmh.edu.mx (J. A. Valles Romero), cleana@upmh.edu.mx (C. L. Morales), jmarquez@upmh.edu.mx (J. M. Rodriguez)
}

\section{To cite this article:}

José Antonio Valles Romero, Cid Leana Morales, Julio Márquez Rodriguez. Mobility Development through Public Transportation, the Case of Mexico City. American Journal of Civil Engineering. Vol. 2, No. 3, 2014, pp. 87-90. doi: 10.11648/j.ajce.20140203.14

\begin{abstract}
In this paper we intend to take the most useful elements of transporting goods and people in order to analyze, diagnose and optimize them, it aims to provide elements of analysis on the info we have identified as priorities diagnosis, the relationship shows direct correlation between population density and the number of trips taken by its inhabitants and consumer products, in addition to deviations due to the characteristics of such areas, many variables are taken to try to diagnose the way they are doing the main, as well as the diagnosis, this analysis is crucial in the design of a reorganization strategy that gives priority of transportation.
\end{abstract}

Keywords: Transport and Urban Development, Organization of Transportation, Urban Logistics, Growth of Developed Countries

\section{Introduction}

Cities that have a population ranging 1 and 2 million people will experience the highest growth in the next 20 years.

Trend turns already visible declining growth rates megacities and growing cities that approximate million. But these cities are often in developing countries, i.e. in less urban systems provided quality public transport.

There is a strong relationship between mobility and income. Creating wealth means that people and goods can move easily and quickly. The relationship between the number of daily trips per capita income and is highly significant: despite revealing counterexamples but minority, the countries with the strongest mobility have the highest GDP per capita.

However, although the relationship between mobility and development is strong, it does not imply a transportation extension and above all individual means of transport, supports the growth of developed countries. The model -based development urban sprawl, spatial specialization and its corollary, increased transport times, leads to additional costs and "des economy" that generates congestion, health problems due to pollution, the stress, impacts environmental, lost man hours and delays in delivery of the goods transported, the consequences result in a financial, social and human cost that is always paid by someone: the city dweller, the company, the employee or the community. This led to imagine another model sustainable city that involves a reorientation of urban transport options where looms.

We have studied the main features of Mexico City as growth, economic and demographic conditions, mobility and degree of motorization, with intent to identify not only the environment in which transport companies operate, but also the relationship between transport and urban development [1].

If really want to avoid anarchic growth in cities, should make a greater effort in investigating the specific effects that the changes in the transport system or at least the new infrastructure (second floor, etc. backbones) and services [2].

Displacements in urban areas are secured by a combination of modes, which vary depending on the context. These modes form a system and that system is exactly a whole which should be considered when defining effective mobility policies.

\section{Theoretical Foundations}

Within systems increasing attention is accentuated by the international community to sustainable mobility schemes, where public transport and non- motorized transport should play a major role, although keeping a complementary role for the automobile. The observation made in various 
regions of the world indicates that these public transportation and other minor modes have not received sufficient attention and effort to meet the mobility needs in satisfactory condition. Managers are then faced with a triple challenge in coming years:

- Challenge of the current shortfall, while qualitative and quantitative public transport in its various forms;

- Challenge of urban growth that creates new needs to meet because of rising populations and the lengthening of travel distances;

- Challenging the environment, energy and climate change leading to find a new balance between individual modes and collective modes, both in the developed countries as in the developing.

These three challenges lead to the necessary strengthening of collective transports and non- motorized transport, which should mobilize significant financial resources for both exploitation and renewal of existing networks as needed for mass transportation investments to meet the needs future.

From the statistics, surveys, interviews and surveys applied, the characteristics of the population as a starting point for defining a policy of city transportation, education, the needs and preferences of users emerge depend on the success of the transport policy of the city.

\section{Methods}

Through specialized testing equipment for monitoring mobility and tracking see picture 1 , we can measure the conditions of the population in Mexico that is characterized by the high percentage of young people.

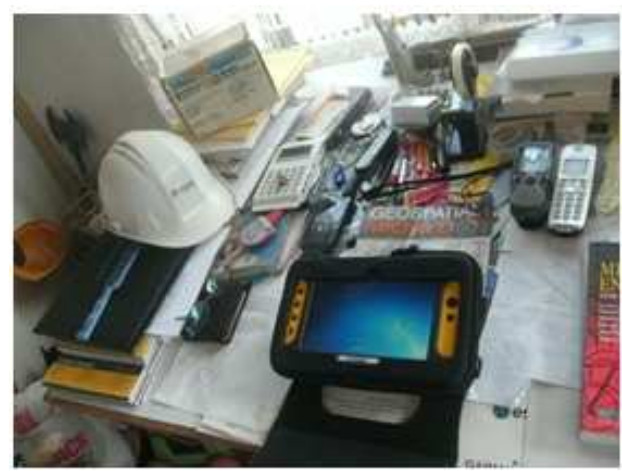

Picture 1. Experimentation specialized equipment

Regarding income levels, the population structure reveals a strong distribution problem. One thing very important because it is the users of the public transportation which is clearly missing in the distribution of income, many of the financial problems of the public transport companies due to the low rate [3].

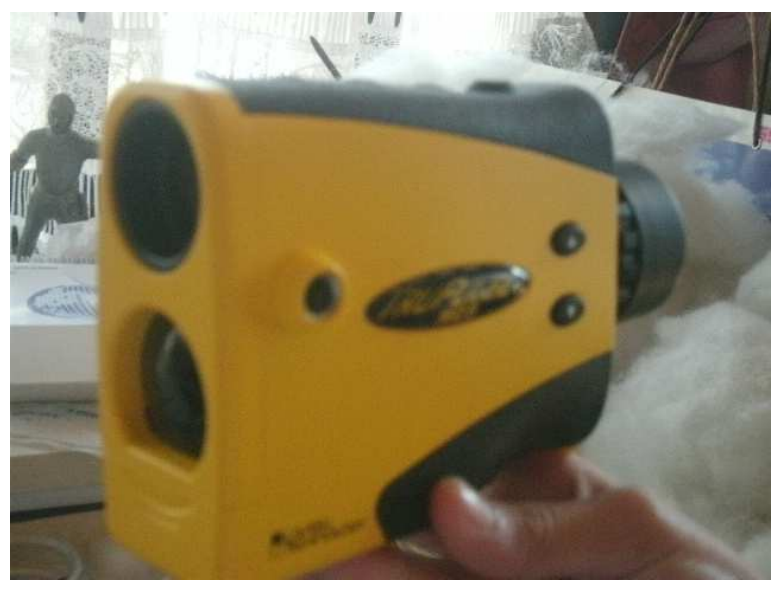

Picture 2. Equipment for tracking and tracing

The housing characteristics are another important element of the urban transport policy at least by three reasons:

First as result of the high correlation between income level and population mobility. Less urbanized, and with lower levels of income (Tláhuac, Iztapalapa, Milpa Alta and Cuajimalpa) delegations are the least recorded daily trips per person (just over two) [4].

Also associated with this type of correlation between housing and mobility a high ratio frequently between housing type and mode (although the phenomenon of mode selection is much more complex and more dependent on factors such as. coverage of such modes, capacity, frequency step, the treatment of users, etc.) for example , one would generally expect luxury housing areas are more dependent modes of transport for private use : own cars, taxis, buses exclusive, and less of the collective modes of transport and even less of the really massive modes.

Second best transportation adapt to the characteristics of the service areas such as population density, is essential that these areas have a high enough population density to make public transport visible [5].

Third; linking housing with transportation refers to the approach that the workplaces are really close to residential areas to reduce commuting as possible.

This approach considers the problem of commuting for work. If consider that they only represent about $25 \%$ of trips, we should take into account the educational, commercial, recreational, etc.

There is some concessive that a metro line is operatively justified if we have over 30,000 passengers per hour per direction, What highlights the complexity of the problem and the need for more study on localization lines were performed with the electronic equipment shown in picture 2 and 3.

Another variable is the cost of land varies inversely with the distance between the central areas of the city, to increase accessibility as the value of land increases the value of the property, invariably responds to changes in the cost and quality of transportation service. 


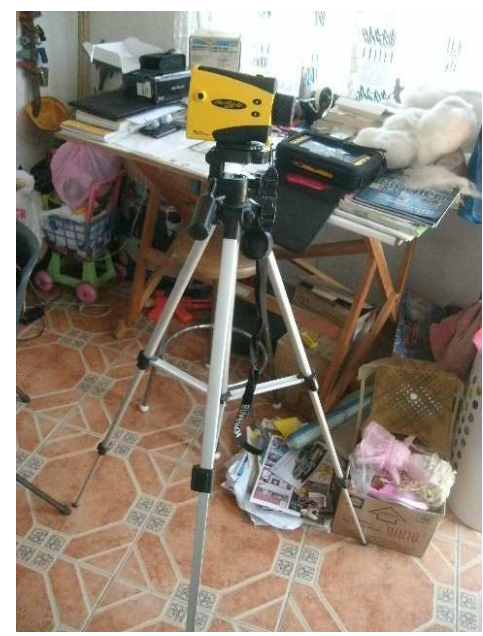

Picture 3. Equipment for mobile data

\section{Results and Discussion}

The magnitude of the problem that exists for moving millions of people and goods in the city reaches levels that are doing unmanageable; Daily-person to transfers hours consumed nearly 3 million, which implies an investment of time equivalent to more than three hundred thousand working days of eight hours.

People come to do business in a state of fatigue and retention and the products are abused, they can begin to assess the impact of the current operation of transport in the productivity of the economic machine. In particular quarter of emissions in the atmosphere comes from the use of private transport.

The conditions under which conducts the daily movements of people and products in the city are difficult issues but are also a direct result of poor transport operation.

Take a trip inside the public transport system in the city of Mexico involves a huge amount of discomfort and problems for users and products.

Some of these problems could be considered subjective or unimportant. Such is the case of having to endure bad smells, unsafe products, and some attacks on human dignity, besides the discomfort offered by vehicles on the way [6].

Other important variables that involve high costs for users and consumers: excessive walking tours, the shooting and expect promotions which may even resemble real approaches where the strongest are imposing; frequent insecurity not only by excessive speed and the constant and unpredictable forced detentions, but even by the authorities , customs and inspections.

The severity and frequency of conflict requires study and analyze them seriously. Course, not all users and products have the same problems, not all modes offer the same type of service.

Even private motorists who literally enclose and isolate the other drivers and the general public, they go through various calamities, from other drivers (especially of official vehicles) of the surprises of road (potholes, detours works, obstacles cleaning and bumpers, etc.) and your own vehicle.

The transport systems are one of the most complex and controversial issues within cities [7].

In the specific case of Mexico City the last three years is allocated nearly a third of the budgetary resources of the Federal District to items directly related to transportation and roads [8].

For many people the problem of transporting cargo and people has become normal, everyday so it does not seem as severe, the elements of this study showed otherwise.

But achieving these goals would only be possible in the medium term and even to certain conditions, among which it is subject: the professionalization of staff and procedures, organization of real companies, several changes in the tariff policy, use of better technologies for operation and maintenance, and so on.

Considering the above, the aim is to contribute to the explanation of the causes of transport crisis in the city of Mexico and from the diagnosis, explore some of the tuning options to cope.

It is essential to proceed with extreme objectivity and abandon thoughts that have dominated the study of transport. So negative is a priori approach to catastrophic, as unfortunate blind defense of unilateral action.

We study various deficiencies in transport policy, but also recognize the significant achievements that have taken real effort and sacrifices to the population. While this description does not replace the detailed analysis of these measures than we hope to serve as a basis for the experiences and values that must be preserved to take advantage as the public interest or at least strive not repeat those that have been confirmed as useless.

It is noteworthy that many officials arriving means of transport are practically almost deceived by the same specialists in urban transport, which basically propose every six years the same.

The creation of this transportation study may be useful not only to staff, but also for all those interested in proposing solutions for transport. There is a marked trend in other cities to emulate Mexico City.

One of the main reasons for the lack of better results on transport policy in cities is poor quality and quantity in the investigation to form a comprehensive theory of urban [9] transportation.

We can distinguish six approaches to the study and analysis of the transport problem, although they are not mutually exclusive.

1. - Analyze transportation as a congestion problem. Thus, the models in the interest to eliminate this congestion, particularly that caused by private cars, by building more infrastructures. It is characteristic of the automobile society and their advocates.

2. - Analyze transport in their interaction with the urban development, identifying transport as a cause or consequence of the growth and diversification of urban characteristics. This approach is much more analytical and 
deep. It expected to help stimulate serious discussion of the interplay between transport and development.

3. - Analyze transportation with economic approach focusing on performance of the financial resources of the government and transport companies. The problem is that there is a neglect of the social costs is so large and frequent in the field of transport.

4. - Analyze transport in their technological characteristics. He called for comprehensive coordination that emphasizes the efficient allocation of transport services according to their technological characteristics trying to meet the needs of users but without damaging the business economy as characteristics of transportation engineering.

5. - Analyze how decisions within the urban transport are taken. So trying to find a way to achieve democratic participation in decisions that affect many, and are taken unilaterally by some officials or technicians who believe they have the right or the right to do so. There is a risk of manipulation and dominance of particular interests.

6 - Analyze the environmental impact of road transport and cause in its construction, operation and disposal, in order to actually reduce the current levels of environmental impact is enough to take an organization especially public transport, while having a direct contribution lower than the private car, it is strategic to set up a transport system with a less polluting and more efficient profile [10].

One of the premises confirmed in this research has been that the movement of people and goods in the Mexico City must rely more intensively on public transportation in the use of private transport.

The aim is to combine an analysis of issues that are seemingly distant but sheds analysis of our work, in this sense, and given the institutional framework and the specific characteristics of transport is review the actions taken or feasible to perform for efficient transport system, and a more rational use of economic resources and oriented transport through funding, grants or investment in public transport to implement a more comprehensive and efficient operation of public and private modes, as well as modes of fright.

\section{Conclusion}

This analysis presents a reorganization strategy that gives priority to transport modes, related to population density and the number of trips taken its inhabitants, plus the deviations due to the characteristics.

The characteristics of each types of service as an important aspect of the analysis, coordination and integration of the public transport system issue. The competition between public transport and private focusing on three different aspects: the number of vehicles, roads and freight, a priority is to make the overall approach of the transportation problem in the City.

\section{References}

[1] Backhoff Pohls, Miguel Angel (2005). Transport and geographic space. Computing approach. UNAM and Mexican Transportation Institute, Mexico (2005)

[2] Black, William. Transportation: A Geographical Analysis. Guilford Publications, New York (2003)

[3] Bruton M.J. Introduction to Transportation Planning. Hutchinson Technical, Education (2007)

[4] Holguin - Veras, Jose, Thorson, Ellen. Trip Length Distributions in Commodity Based and Trip Based Freight Demand Modeling. Journal of Transportation Research Board, Vol 1707 (2000)

[5] Kutanoglu, E. Modeling and Analysis of Transportation Flows Created by Ecommerce Transactions. Mack -Blackwell Transportation Center Board Meeting, Fayetteville, AR (2010)

[6] Manheim, Marvin L. Fundamentals of Transportation Systems Analysis. Vol I. The Massachusetts Institute of Technology. MIT Press, Cambridge, Mass. (2006)

[7] Ortúzar Salas, Juan de Dios. Modelling Transport. 2nd edition. John Wiley \& Sons (2007)

[8] Taaffe, Edward; Gauthier, Howard; O'Kelly, Morton. Geography of Transportation. 2nd Ed Prentice Hall, New Jersey (2005)

[9] Thomson, JM Economic Theory of transport. Editorial Alliance (2009)

[10] Wilson, G. Transportation and Traffic Management. Alexander Hamilton Institute Incorporated, New York, USA (2009). 